Brit. Heart F., 1968, 30, 344.

\title{
Some Observations on Haematocrit Changes in Patients with Acute Myocardial Infarction
}

\author{
LUDWIK SEDZIWY*, MICHAEL THOMAS, AND JOHN SHILLINGFORD \\ From the Medical Research Council's Cardiovascular Research Unit, Royal Postgraduate Medical School, \\ London W.12
}

Changes in haematocrit in patients with acute myocardial infarction are the subject of several reports. Burch and DePasquale (1962) and DePasquale and Burch (1963) suggested that the peripheral venous haematocrit was raised in acute myocardial infarction. This was not confirmed by subsequent studies (Conley et al., 1964; Vuopio and Eisalo, 1964) but has recently been supported (Stables et al., 1967). It has also been suggested that a fall in haematocrit may occur during the first few days of the acute illness (Conley et al., 1964; Vuopio and Eisalo, 1964).

With recent interest in the treatment of cardiac infarction by infusions of various solutions, the physiology of haematocrit and plasma volume becomes more important. In the course of haemodynamic study of patients with acute myocardial infarction we have routinely measured central venous haematocrit, and high values and large changes during the first few days after the onset of symptoms have been noted frequently.

The purpose of this paper is to document these observations together with plasma volume measurements made in selected patients. Possible physiological mechanisms responsible for the haematocrit changes and their relevance to infusion treatment of patients with acute myocardial infarction are discussed.

\section{SUBJECTS AND METHODS}

Twenty-seven patients, 23 men 4 women, with unequivocal clinical and electrocardiographic evidence of acute myocardial infarction, admitted to the coronary care unit (Shillingford and Thomas, 1964), were studied. Ages ranged from 46 to 73 , mean $59 \cdot 7$ years. Twentyfive patients (Table I) were selected on the basis of one arbitrary criterion-a central venous haematocrit equal

Received September 14, 1967.

$\star$ British Council Scholar. to or greater than 47 per cent on at least one occasion during the first week of illness. Three patients had a history of chronic bronchitis but no evidence of serious lung disease. Two or more measurements were made in all patients except three who died within 24 hours.

The first measurements were made when the patient was admitted to hospital. In all except six patients this was within 24 hours of the onset of symptoms. Subsequent investigations, as far as possible, were made at the same time of day.

Haematocrit was measured by the Wintrobe method. Central venous blood was taken via an indwelling polyethylene catheter and transferred into heparinized tubes. An aliquot was centrifuged in a Wintrobe tube at $\mathbf{3 0 0 0}$ r.p.m. for 30 minutes. The radius from the centrifuge axis to the tip of the tube was $15 \mathrm{~cm}$.

Serial measurements of plasma volume were made in two patients selected from those in Table I (Cases 22

TABLE I

HAEMATOCRIT DATA

\begin{tabular}{|c|c|c|c|c|c|c|c|c|c|}
\hline \multirow[b]{2}{*}{ Case No. } & \multirow[b]{2}{*}{ Sex } & \multirow{2}{*}{$\begin{array}{l}\text { Age } \\
\text { (yr.) }\end{array}$} & \multicolumn{7}{|c|}{ Day of illness } \\
\hline & & & 1 & 2 & 3 & 4 & 5 & 6 & 7 \\
\hline $\begin{array}{r}1 \\
2 \\
3 \\
4 \\
5 \\
6 \\
7 \\
8 \\
9 \\
10 \\
11 \\
12 \\
13 \\
14 \\
15 \\
16 \\
17 \\
18 \\
19 \\
20 \\
21 \\
22 \\
23 \\
24 \\
25\end{array}$ & $\begin{array}{c}\mathbf{M} \\
\mathbf{M} \\
\mathbf{M} \\
\mathbf{M} \\
\mathbf{F} \\
\mathbf{F} \\
\mathbf{M} \\
\mathbf{M} \\
\mathbf{M} \\
\mathbf{M} \\
\mathbf{M} \\
\mathbf{M} \\
\mathbf{M} \\
\mathbf{M} \\
\mathbf{M} \\
\mathbf{M} \\
\mathbf{M} \\
\mathbf{M} \\
\mathbf{M} \\
\mathbf{M} \\
\mathbf{F} \\
\mathbf{M} \\
\mathbf{M} \\
\mathbf{M} \\
\mathbf{F}\end{array}$ & $\begin{array}{l}49 \\
64 \\
64 \\
60 \\
50 \\
60 \\
64 \\
58 \\
45 \\
64 \\
51 \\
63 \\
47 \\
73 \\
60 \\
56 \\
61 \\
54 \\
67 \\
65 \\
68 \\
58 \\
65 \\
46 \\
70\end{array}$ & $\begin{array}{l}52 \\
49 \\
49 \\
50 \\
52 \\
53 \\
\\
51 \\
46 \\
58\end{array}$ & $\begin{array}{l}54 \\
51 \\
54 \\
49 \\
52 \\
49 \\
53 \\
54 \\
49 \\
44 \\
43 \\
52 \\
50 \\
51 \\
50 \\
50\end{array}$ & $\begin{array}{l}51 \\
49 \\
54 \\
44 \\
50 \\
48 \\
50 \\
54 \\
49 \\
56 \\
39 \\
50 \\
46 \\
48 \\
50 \\
\\
49 \\
49 \\
59\end{array}$ & $\begin{array}{l}45 \\
47 \\
53 \\
\\
46 \\
49 \\
54 \\
57\end{array}$ & $\begin{array}{r}44 \\
43 \\
53\end{array}$ & $\begin{array}{l}48 \\
59 \\
47\end{array}$ & $\begin{array}{l}52 \\
38\end{array}$ \\
\hline
\end{tabular}




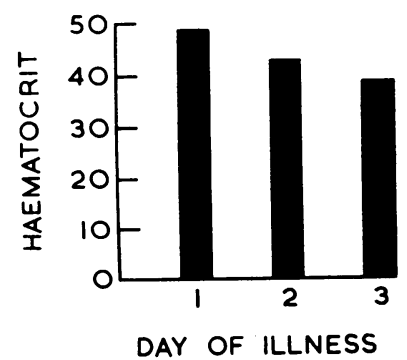

FIG. 1.-An example of falling haematocrit commonly observed in patients with acute myocardial infarction.

and 24) and in two other patients, all men. Plasma volume was measured by the use of radioactive ${ }^{131}$ I human serum albumin (RIHSA), which was dialysed before use. RIHSA (between 7 and $20 \mu \mathrm{Ci}$ ) was injected from a calibrated syringe into the central venous system via the catheter. Blood samples were taken at $10,15,20$, and 25 minutes. The catheter was washed with blood and saline before and after injection and sampling. The amount of RIHSA solution injected was determined by injecting the same volume from the same syringe through a similar blood and saline washed catheter into a $1000 \mathrm{ml}$. flask containing saline and $10 \mathrm{ml}$. concentrated detergent solution (Teepol) (Reeve and Franks, 1956). This was made up to $1000 \mathrm{ml}$. and the radioactivity of an aliquot determined.

For the final calculation of plasma volume, the plasma radioactivity at "zero time", obtained by extrapolation, was used.

Radiological evidence of pulmonary oedema was graded $1-4$ according to severity.

\section{RESULTS}

Haematocrit Changes. Values of haematocrit and the times at which they were obtained are given in Table I. The time scale was made with reference to the onset of symptoms.

Haematocrit on the first day ranged from 46 to 59 per cent; on the second day from 43 to 54 per cent; on the third day from 39 to 59 per cent; on the fourth day from 44 to 57 per cent and on the fifth day from 43 to 53 per cent.

A change of 3 per cent or more in haematocrit during the first week of the illness occurred in 17 patients. In 15 of these, later values were lower than initial values. An example of falling haematocrit in one of these patients (Case 13) is given in Fig. 1. Two patients (Cases 6, 20) showed an increase in haematocrit during the first two days but in one of these (Case 6) a fall of more than 3 per cent followed. An example of increase of haematocrit (Case 20) is given in Fig. 2.

The general clinical state of patients in this group during the period of haematocrit measurement is indicated in Table II.

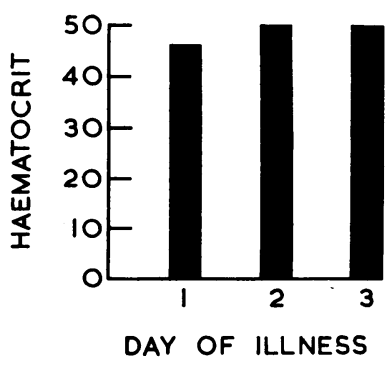

FIG. 2.-An example of increasing haematocrit sometimes observed in patients with acute myocardial infarction.

TABLE II

CLINICAL STATE OF PATIENTS

\begin{tabular}{|c|c|}
\hline Clinical data & $\underset{\text { patients }}{\text { Number of }}$ \\
\hline $\begin{array}{l}\text { Uncomplicated course } \\
\text { Hypotension } \\
\text { Pulmonary oedema } \\
\text { "Shock" with pulmonary oedema } \\
\text { "Shock" without pulmonary oedema }\end{array}$ & $\begin{array}{l}9 \\
4 \\
8 \\
3 \\
1\end{array}$ \\
\hline Total & 25 \\
\hline
\end{tabular}

\section{Plasma Volume}

Patient $A$ (Case 22). A man aged 58, with acute antero-lateral infarction, initially had marked pulmonary oedema, and clinical improvement was later followed by cardiac arrest and resuscitation. Subsequently a shock syndrome developed. The early clinical improvement with resolution in pulmonary oedema was associated with a fall in haematocrit from 49 to 37 per cent (Fig. 3). At the same time plasma volume rose from 30 to $39 \mathrm{ml} / \mathrm{kg}$. Although pulmonary oedema resolved, the heart size, assessed by cardiothoracic ratio, increased from 0.52 to $0 \cdot 60$. The lung fields remained clear for 8 days until cardiac arrest on the 18th day. Plasma volume fell from $39 \mathrm{ml} . / \mathrm{kg} ., 3$ hours preceding arrest, to $34 \mathrm{ml} . / \mathrm{kg} ., 16$ hours afterwards. Haematocrit did not change. The clinical features after cardiac arrest included gross pulmonary oedema, the shock syndrome, and further cardiac enlargement. Six days later he again had cardiac arrest and died.

Patient B (Case 24). A man aged 46, with acute antero-septal infarction, had moderately severe pulmonary oedema which resolved radiologically on the sixth day of illness. Fig. 4 shows the plasma volume change which accompanied a fall in haematocrit from 51 to 48 per cent between the 4th and 6th days. Plasma volume increased from 33 to $36 \mathrm{ml} / \mathrm{kg}$. These changes took place at the time that radiological pulmonary oedema cleared, though fluid balance measurement did not show significant diuresis after mersalyl.

Patient C. A man, aged 66 years, with acute anterolateral infarction, had mild pulmonary oedema which rapidly resolved after administration of a diuretic. 


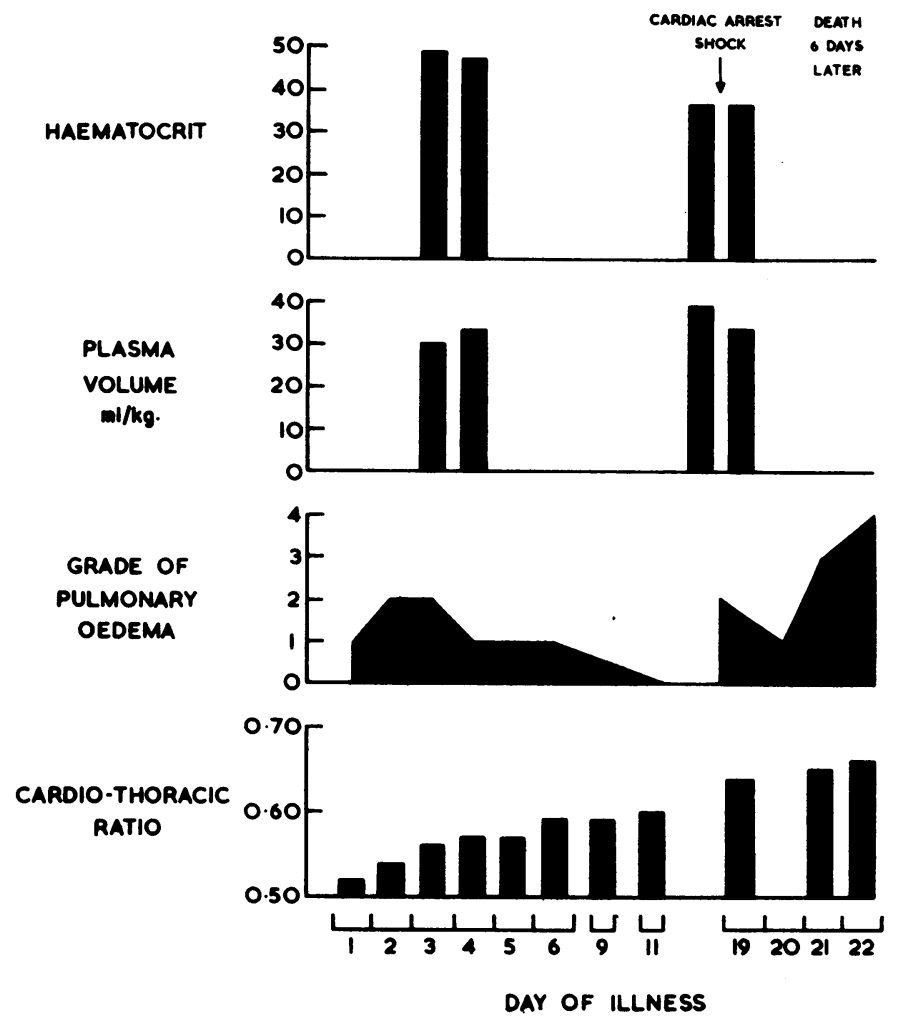

FIG. 3.-Haematocrit and plasma volume changes observed during resolution of pulmonary oedema and later cardiac arrest in Patient $\mathrm{A}$.

Fig. 5 shows the plasma volume change which accompanied an increase in haematocrit from 38 to 40 per cent between the 1st and 3rd days. Plasma volume fell from 54 to $48 \mathrm{ml} . / \mathrm{kg}$. These changes took place at the time that radiological pulmonary oedema cleared, but in this instance the patient had a net fluid loss (urine outputfluid intake) within that period of approximately 2.51 . At the 14th day haematocrit was 40 per cent but plasma volume had fallen further to $43 \mathrm{ml} . / \mathrm{kg}$.

Patient D. A man, aged 64 years, with acute posterior infarction, had both left and right ventricular failure associated with radiological pulmonary oedema and a raised central venous pressure (right heart pressures were RA mean 9, RV 40/9; PA 40/19 mm. Hg). No peripheral oedema was present. Clinical improvement with resolution of pulmonary oedema and also a fall in central venous pressure occurred initially but later pulmonary oedema returned transiently. Fig. 6 shows the haematocrit and plasma volume changes observed.

On the second day when pulmonary oedema was present, haematocrit was 38 per cent, with plasma volume $39 \mathrm{ml} . / \mathrm{kg}$. Seventeen days later, when pulmonary oedema had resolved radiologically and central venous pressure had returned to normal limits, haematocrit had fallen to 33 per cent and plasma volume had risen to $42 \mathrm{ml} . / \mathrm{kg}$. On the 27th day, when pulmonary oedema had returned, haematocrit had increased once more to 36 per cent and plasma volume had fallen to 37 $\mathrm{ml} . / \mathrm{kg}$. At that time, right ventricular end-diastolic pressure was normal.

\section{Discussion}

The haematocrit values from central venous blood given in this report are not subject to some criticisms which may be made of peripheral venous sampling, in that no venous constriction is involved and possible local vascular changes during sampling are unlikely.

With respect to the haematocrit data, no selection of patients was made other than on the arbitrary criterion of haematocrit of 47 per cent or above at some time during the first week of illness. The patients had a wide range of severity of clinical illness, ranging from an uncomplicated course to 

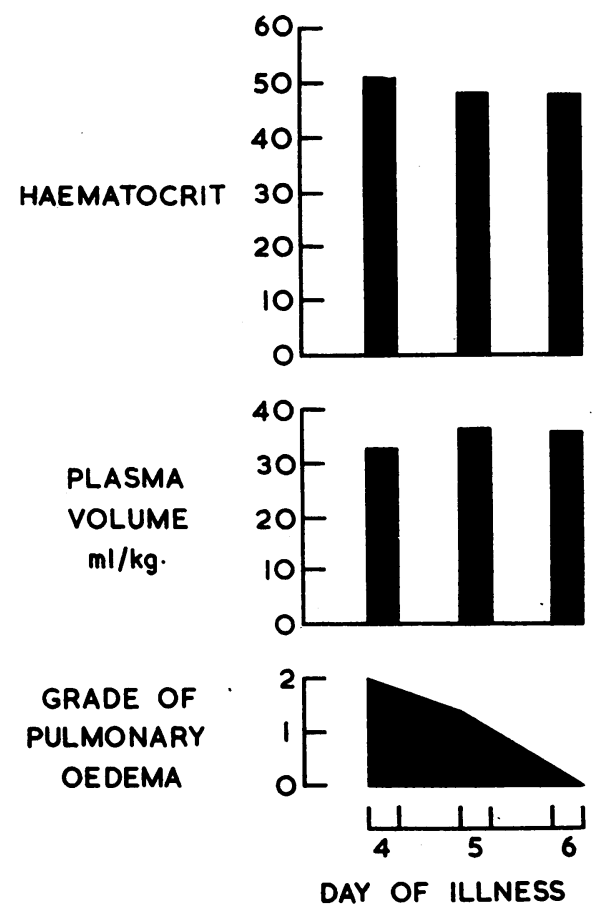

FIG. 4.-Haematocrit and plasma volume changes observed during resolution of pulmonary oedema without diuresis in Patient B.

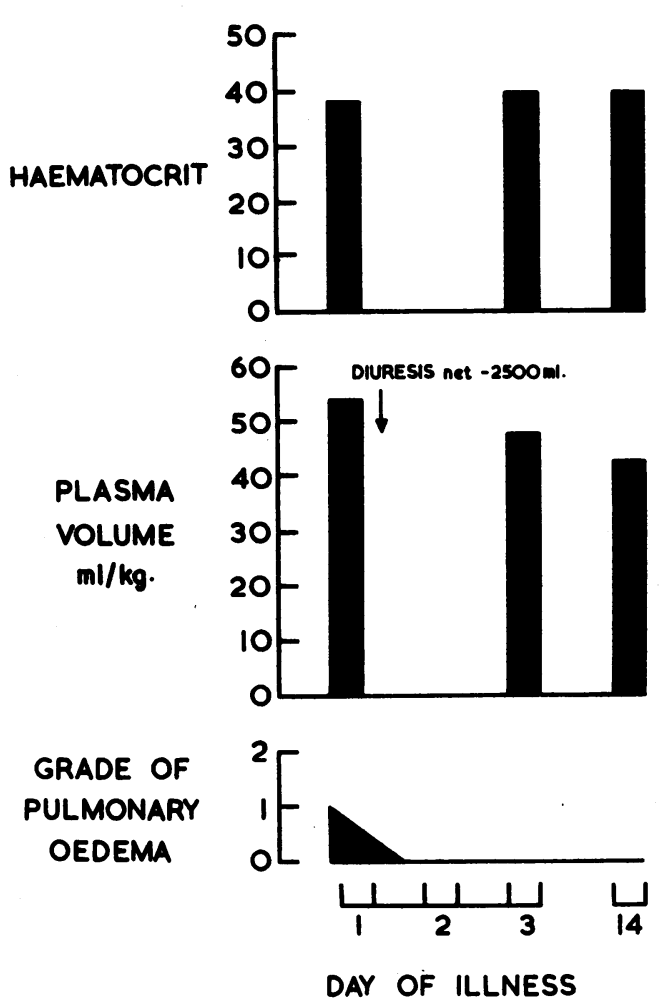

Fig. 5.-Haematocrit and plasma volume changes observed in Patient $\mathbf{C}$ in whom resolution of pulmonary oedema was associated with a large diuresis.
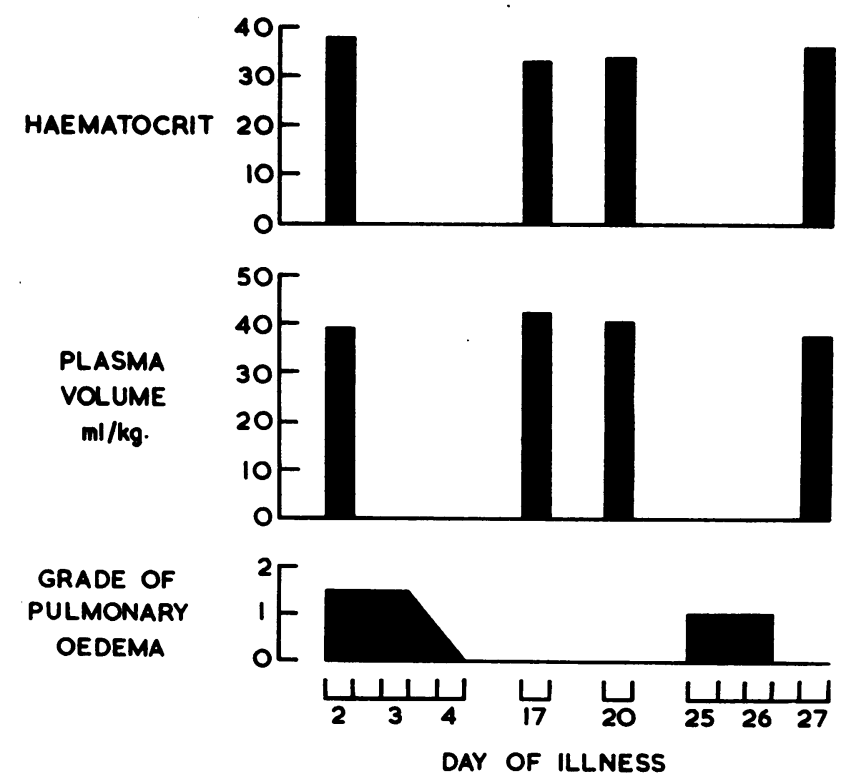

FIG. 6.-Haematocrit and plasma volume changes observed in Patient $D$ in whom pulmonary oedema initially resolved but later transiently returned. 
extreme cardiovascular failure. Appraisal of the haematocrit changes during the first week showed a general tendency for a fall to occur. Comparison of the initial level of haematocrit and subsequent changes with the clinical picture did not show a simple correlation. High values and large changes were found in patients with different clinical problems, including pulmonary oedema, extreme cardiovascular failure, and "shock", and also in those with uncomplicated illness.

Explanations of the changes observed, in terms of physiological mechanisms, may be divided into two groups: first, those involving an initial loss of plasma from the vascular space with subsequent return: second, those involving possible changes in circulating red cell volume. The first possibility is more likely, since rapid changes in circulating red cell volume are, in man, mainly confined to red cell loss which was limited to the amount of blood taken for investigation.

Some factors that may be relevant to haematocrit changes are illustrated by the selected individual patient examples with plasma volume measurements. It seems apparent from the studies made in Patients $A, B$, and $D$, that the formation of pulmonary oedema as assessed by radiology is associated with a fall in plasma volume and a reciprocal increase in haematocrit. Resolution of pulmonary oedema leads to converse changes. In Patient $\mathrm{C}$, however, the haematocrit and plasma changes during resolution of pulmonary oedema, which were in the opposite direction, were probably the consequence of a large diuresis. A diuresis within the first two days also occurred in the two other exceptional patients (Cases 6 and 20; Table I, Fig. 2) who showed an increase in haematocrit at this time.

Alterations in plasma volume associated with pulmonary oedema do not provide a complete explanation for the changes in haematocrit observed. In particular high initial values with subsequent fall were sometimes seen in patients who had no radiological oedema and an uncomplicated clinical picture. Relevant factors common to most patients include possible dehydration due to fever and sweating in the acute phase of the illness, but in many this was limited to a slight moistness of the skin. Other factors may be related to the increased adrenergic drive which has been recently demonstrated in patients with acute myocardial infarction by measurements of urine catecholamines (Valori, Thomas, and Shillingford, 1967). Experimental work with noradrenaline infusion in dogs has illustrated reduction of systemic vascular capacity due to increased venomotor tone (Rose et al., 1962). This effect might be responsible for changes in plasma volume and haematocrit (Albert, 1963).
The significance of the haematocrit and plasma volume changes with respect to infusion treatment of patients with acute myocardial infarction is not clearly defined. This study suggests that the formation of pulmonary oedema is associated with a fall in plasma volume, but it is likely that changes of similar magnitude occur in less seriously ill patients as well as the patients who are most ill with the shock syndrome. Whether the plasma volume fall in itself calls for replacement treatment is debatable but continued study is necessary to show whether infusions confer benefit by other mechanisms.

\section{SUMMARY}

Serial measurements of central venous haematocrit have been made in patients with acute myocardial infarction. A tendency for some patients to have initial high levels, subsequently falling, has been observed. Measurements of plasma volume have indicated that reciprocal changes in plasma volume are related to the formation and resolution of pulmonary oedema assessed by radiology. High haematocrit with subsequent fall may also occur in patients without pulmonary oedema. Possible physiological mechanisms and their significance with respect to treatment are discussed.

The authors wish to thank Mr. Peter Burgess and Miss Sunja Marrington for technical assistance, and Miss Jean Powell who drew the diagrams.

\section{REFERENCES}

Albert, S. N. (1963). Blood volume. Anesthesiology, 24, 231.

Burch, G. E., and DePasquale, N. P. (1962). The hematocrit in patients with myocardial infarction. $\mathcal{f}$. Amer. med. Ass., 180, 63.

Conley, C. L., Russell, R. P., Thomas, C. B., and Tumulty, P. A. (1964). Hematocrit values in coronary artery disease. Arch. intern. Med., 113, 170.

DePasquale, N. P., and Burch, G. E. (1963). Hematocrit in women with myocardial infarction. $\mathcal{F}$. Amer. med. Ass., $183,142$.

Reeve, E. B., and Franks, J. J. (1956). Errors in plasma volume measurement from adsorption losses of albumin $-\mathrm{I}^{131}$. Proc. Soc. exp. Biol. (N.Y.), 93, 299.

Rose, J. C., Kot, P. A., Cohn, J. N., Freis, E. D., and Eckert, G. E. (1962). Comparison of effects of angiotensin and norepinephrine on pulmonary circulation, systemic arteries and veins, and systemic vascular capacity in the dog. Circulation, 25, 247. 
Shillingford, J. P., and Thomas, M. (1964). Organisation of unit for intensive care and investigation of patients with acute myocardial infarction. Lancet, 2, 1113.

Stables, D. P., Rubenstein, A. H., Metz, J., and Levin, N. W. (1967). The possible role of hemoconcentration in the etiology of myocardial infarction. Amer. Heart $\mathcal{F}$., 73, 155.
Valori, C., Thomas, M., and Shillingford, J. P. (1967). Free noradrenaline and adrenaline excretion in relation to clinical syndromes following myocardial infarction. Amer. F. Cardiol, 20, 605.

Vuopio, P., and Eisalo, A. (1964). Hematocrit values in men with myocardial infarction. Ann. Med. intern. Fenn., $53,39$. 